\title{
Blocking All Paths to an Iranian Bomb: How the West Can Avoid a Nuclear Maginot Line
}

\section{Citation}

Allison, Graham, and Oren Setter. 2014. “Blocking All Paths to an Iranian Bomb: How the West Can Avoid a Nuclear Maginot Line." Discussion Paper, Belfer Center for Science and International Affairs, Harvard Kennedy School.

\section{Published Version}

http://belfercenter.ksg.harvard.edu/publication/24338/

blocking_all_paths_to_an_iranian_bomb.html

\section{Permanent link}

http://nrs.harvard.edu/urn-3:HUL.InstRepos:17190499

\section{Terms of Use}

This article was downloaded from Harvard University's DASH repository, and is made available under the terms and conditions applicable to Other Posted Material, as set forth at http:// nrs.harvard.edu/urn-3:HUL.InstRepos:dash.current.terms-of-use\#LAA

\section{Share Your Story}

The Harvard community has made this article openly available.

Please share how this access benefits you. Submit a story.

\section{Accessibility}




\section{BLOCKING ALL PATHS TO AN IRANIAN BOMB}

HOW THE WEST CAN AVOID A NUCLEAR MAGINOT LINE

BY GRAHAM ALLISON \& OREN SETTER
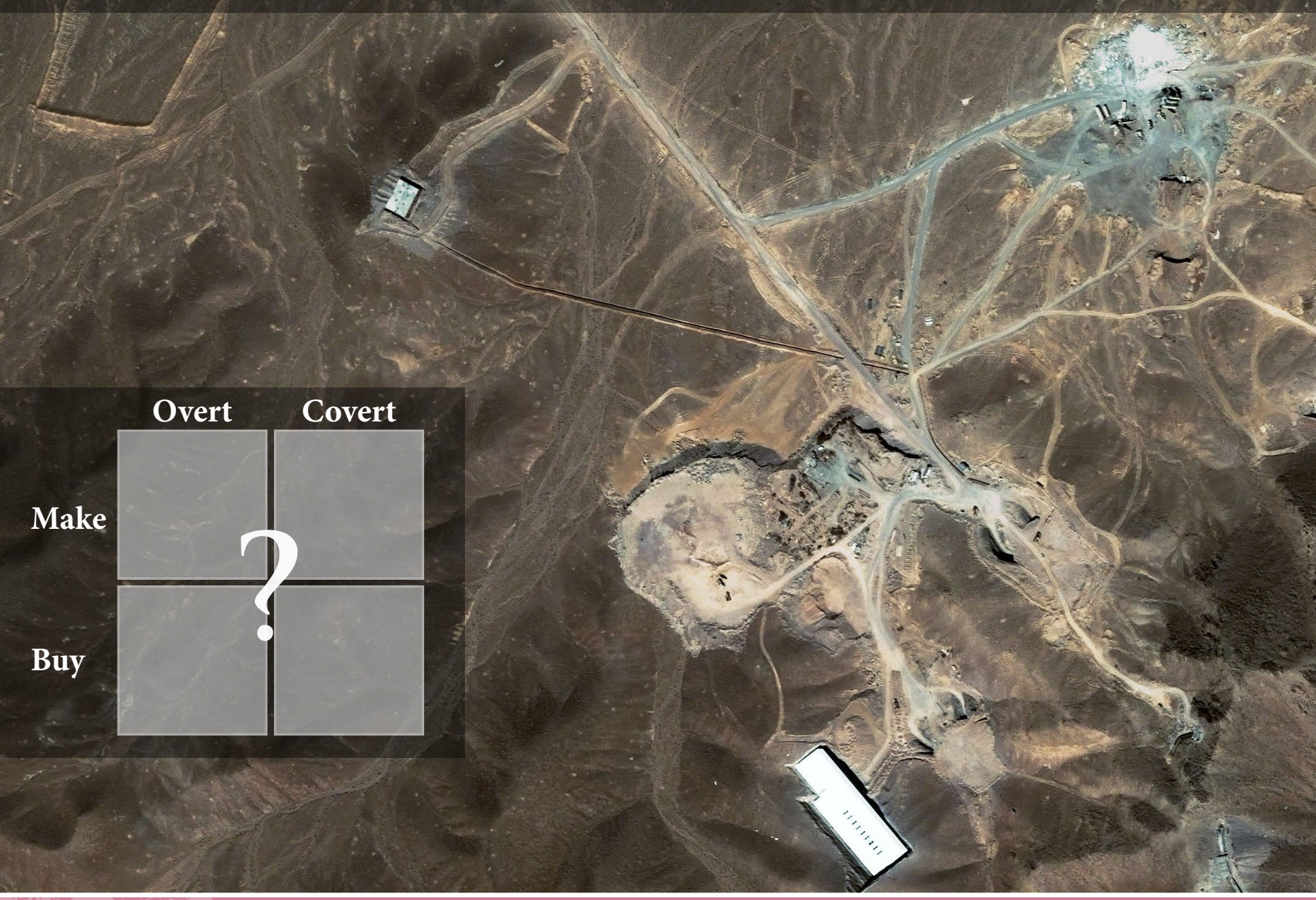

HARVARD Kennedy School

BELFER CENTER for Science and International Affairs

JUNE 2014 


\section{Belfer Center for Science and International Affairs}

\section{John F. Kennedy School of Government}

Harvard University

79 JFK Street

Cambridge, MA 02138

Fax: (617) 495-8963

Email: belfer_center@hks.harvard.edu

Website: http://belfercenter.org

\section{Copyright 2014 President and Fellows of Harvard College}

The author of this report invites use of this information for educational purposes, requiring only that the reproduced material clearly cite the full source:

Allison, Graham, and Oren Setter. "Blocking All Paths to an Iranian Bomb: How the West Can Avoid a Nuclear Maginot Line.” Discussion Paper, Belfer Center for Science and International Affairs, Harvard Kennedy School. June 2014.

Cover photo: A file satellite image taken Sunday Sept. 27, 2009, provided by DigitalGlobe, shows a suspected nuclear enrichment facility under construction inside a mountain located north of Qom, Iran. (AP) 


\section{About the Authors}

Graham Allison is Director of the Belfer Center for Science and International Affairs and Douglas Dillon Professor of Government at Harvard's John F. Kennedy School of Government. The "Founding Dean" of the modern Kennedy School, Dr. Allison has served as Special Advisor to the Secretary of Defense under President Reagan and as Assistant Secretary of Defense under

President Clinton. Dr. Allison's first book, Essence of Decision: Explaining the Cuban Missile Crisis (1971) ranks among the all-time bestsellers with more than 450,000 copies in print. His latest book (2013), Lee Kuan Yew: The Grand Master's Insights on China, the United States and the World (co-authored with Robert Blackwill), has been a bestseller in the US and abroad. His previous book, Nuclear Terrorism: The Ultimate Preventable Catastrophe, now in its third printing, was selected by the New York Times as one of the "100 most notable books of 2004."

Oren Setter is Research Fellow with the Project on Managing the Atom and International Security Program at Harvard Kennedy School's Belfer Center for Science and International Affairs. He holds a B.Sc. in Physics and Mathematics and a Ph.D. in Decisions and Operations Research, and has over fifteen years of experience as a program manager and researcher in the field of defense technology. Dr. Setter has published several peer-reviewed journal articles and book chapters and has been an adjunct lecturer at the Recanati Business School in Tel-Aviv University.

\section{Acknowledgments}

We acknowledge the helpful comments and suggestions of Matthew Bunn, Gene Gerzhoy, Olli Heinonen, Martin Malin, Steven Miller, Laura Rockwood, and the Belfer Center's Project on Managing the Atom seminar participants. We also thank Andrew Wojtanik for his superb research assistance. All remaining errors are, of course, ours. The opinions expressed in this paper are ultimately our own and do not reflect that of any organization with which we are affiliated. 


\section{Executive Summary}

French Minister of War Andre Maginot became famous among military strategists for his fixation on a single route of attack that led to fatal neglect of alternatives. Seeking to defeat a German invasion along the primary East-West axis, Maginot constructed an impregnable line of fortifications in the 1930s that succeeded in preventing the attack he most feared. But when German panzers outflanked that line and rolled through Belgium in 1940, their attack from the rear led to France's surrender in just six weeks.

In concentrating so much of their mindshare on imposing constraints on Iran's known nuclear facilities at Natanz, Fordow, and Arak, are the US and its five negotiating partners at risk of creating a nuclear Maginot line? ${ }^{1}$

In the world of business, when a firm wants a product, the first question it asks is: make or buy. Quite often, it is the latter. In highly competitive markets, for example, next-generation personal computing devices, Apple and Google also ask: overt or covert. While occasionally they publicize in advance the features of a product they will bring to market in the year ahead, more often (for example, in the case of the iPad), they develop the product in the secrecy of their own labs - and only then announce what they have done.

Graphically, these two dimensions translate into the $2 \times 2$ table on the cover that serves as the framework for this analysis. For thinking about the challenge Iran's nuclear program poses to the US and its allies, it raises two key questions.

First, if in the next several years, Iran is found to have a nuclear bomb, along which of the four paths will it have succeeded? Readers should fill in the boxes in figure 1 below, putting 1 in the quadrant they judge will be Iran's most likely path for acquiring the bomb and 2-4 for the second, third, and fourth. In our informal poll of associates, answers were split between "make/covert" and "make/overt," with "buy/covert" in third place.

Figure 1

Overt Covert

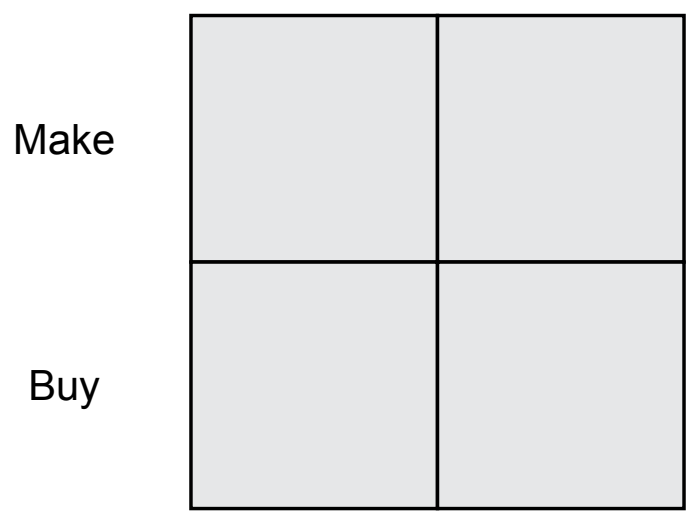

Commonly referred to as the "P5+1," these are the US, UK, France, Russia, China, and Germany. 
Second, in assessing the allocation of the P5+1 governments' interest, energy, and effort to meet the challenge posed by Iran's nuclear ambitions, the reader is again invited to fill in the quadrants in figure 2 below, putting 1 in the box that is consuming most of the attention, and 2, 3, and 4 for the others. Here, the same informal poll yielded a consensus around the make/overt option.

Figure 2

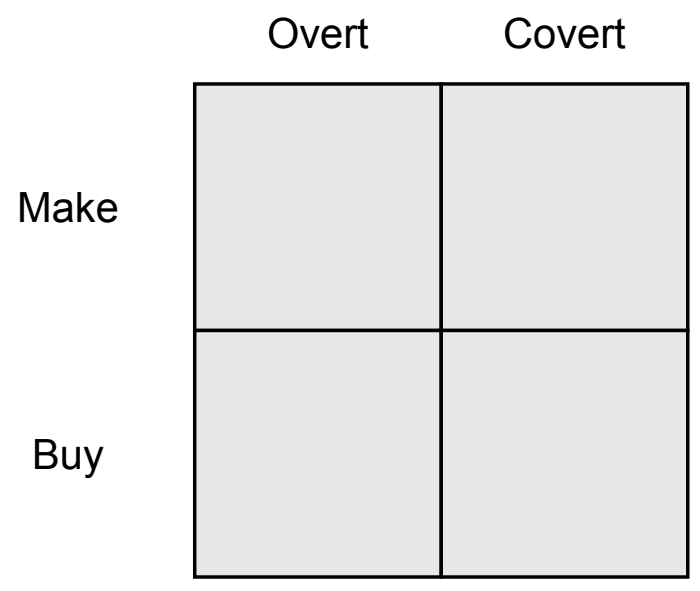

With negotiations ongoing between Iran and the P5+1 about specific constraints on nuclear activities at Iran's overt, declared sites, it is understandable that public debate focuses mostly on this path. In this spirit, the interim agreement reached in November essentially halts Iran's nuclear advance at the 9,400 centrifuges currently spinning and a stockpile of 6-7 bombs' worth of lowenriched uranium (LEU) and requires Iran to dilute or convert to oxide nearly one bomb's worth of $20 \%$ enriched uranium produced prior to the agreement. Negotiations over constraints that could be extended for a decade or beyond are focused on: transforming the heavy-water reactor at Arak to prevent it from producing plutonium for a bomb; capping the number and capability of centrifuges used to produce enriched uranium; reducing stockpiles of enriched uranium; and introducing a host of monitoring and safeguard mechanisms. Summarized in a single measurement, these limits seek to verifiably and significantly extend the "breakout time": the time required for Iran to produce its first bomb's worth of highly enriched uranium at these facilities.

The broader question, however, is: how effective will these constraints be in meeting the bottom line objective, namely, preventing Iran from acquiring a bomb? Maginot's success in blocking a direct attack along the path he fortified did not excuse his failure to defend his country.

If negotiators succeed in reaching an agreement, members of Congress, the larger policy community, and America's allies will debate the adequacy of what is achieved at the negotiating table as they consider the repeal or waiver of legislated sanctions. Assessing the contributions of any agreement to the central objective - no Iranian bomb - thus requires considering the agreement's impact along all azimuths. Indeed, as the P5+1 consider where to spend their limited leverage in negotiating a combination of constraints on Iran's overt program and transparency about Iran's nuclear activities, it is essential to think clearly about all the paths Iran could take to the bomb and 
ask how specific terms in a negotiated agreement advance, or alternatively retard, efforts to stop Iran along all such paths.

Our purpose in this paper is to challenge the analytic community to pause and examine the larger questions as carefully as it has analyzed constraints on Iran's declared nuclear facilities. To jump start that debate, we begin with the best five conclusions we have reached so far:

- The tighter the constraints and transparency on Iran's overt nuclear program, the higher the relative likelihood Iran will try to obtain a nuclear bomb through a different path.

- Combining the "overt/make" and "covert/make" options, Iran could take a hybrid path to a bomb in which it diverts LEU or $20 \%$ enriched uranium from its declared facilities overnight to a covert enrichment facility to produce high-enriched uranium (HEU). An agreement that requires Iran to eliminate or convert LEU or $20 \%$ enriched uranium to fuel rods would reduce this risk.

- Combining the "covert/make" and "covert/buy" paths, a second hybrid option would be to buy fissile material from abroad (namely, North Korea) and then make a weapon at a covert site. This troubling scenario highlights the need to resolve concerns regarding the "possible military dimensions" to Iran's nuclear program and to pursue Iran's verifiable commitment to refrain from such activities in the future.

- While current negotiations are focused primarily on curbing Iran's progress at overt facilities, they also offer an opportunity to try to impact covert (make, buy, or hybrid) paths, to increase the P5+1's confidence that such paths would be quickly detected, and to provide the international community with tools to react quickly if needed. Specific terms may include, though are not limited to, the following:

- A requirement that Iran must ratify and implement the IAEA Additional Protocol, which grants the IAEA greater authority to inspect all aspects of a country's nuclear fuel cycle, and adhere to the modified Code 3.1, which requires nations to provide design information for all nuclear-related facilities before construction begins.

- Full accounting and transparency of Iran's:

- Centrifuges: where all key components have been manufactured and stored, how many, and what types.

- Uranium mining and milling and stocks of yellowcake.

- Procurement of sensitive materials (i.e., maraging steel, advanced carbon fiber).

- Select dual-use items, such as vacuum equipment and motor drives used in enrichment.

- A verifiable cap on Iran's production of advanced centrifuges.

- Allowing (and requiring) Iran to meet its verified nuclear-related purchasing needs through legitimate channels, while making clear that any illicit trade constitutes a violation of the agreement. 
- Monitoring of Iran's nuclear research and development (R\&D) efforts.

- Collaboration on peaceful nuclear R\&D projects to keep Iran's cadre of nuclear scientists and engineers meaningfully employed and engaged.

- An Iranian commitment not to conduct covert nuclear-related activities - and not to buy nuclear material from abroad or collaborate with countries that are not parties to the Nuclear Non-proliferation Treaty (NPT).

- A requirement that Iran must ratify the Comprehensive Nuclear Test Ban Treaty (CTBT) and refrain from constructing an underground nuclear test site.

- An invitation for Iran to participate in future Nuclear Security Summits.

- As a complement to a negotiated agreement, and to ensure that it will be enforced, a $\underline{\mathrm{UN}}$ Security Council resolution that authorizes the members to take action if Iran is caught covertly making or buying nuclear material could help deter Iran from deciding to do so. 


\section{Detailed Analysis}

\section{Background}

The ongoing negotiations between Iran and the P5+1 over a comprehensive nuclear agreement are intended to resolve longstanding disagreements about Iran's nuclear program in exchange for relief from sanctions imposed by the US, UN, and European Union. While implementation of the interim agreement — officially known as the "Joint Plan of Action" (JPOA) — signed in November is a step forward, the way ahead is long and complicated, and success is far from certain.

The key challenge facing the P5+1 negotiators is to ensure that Iran's nuclear program is peaceful. Framed in terms of an operational objective, negotiations aim to apply as many verifiable limitations on Iran's nuclear program as possible to greatly reduce the likelihood that Iran could obtain a nuclear weapon before being detected and stopped.

Most of the public discussion has focused on how to constrain activities at Iran's known and declared nuclear facilities, including enrichment plants at Natanz and Fordow and the Arak heavywater reactor, and on suspected military dimensions of Iran's nuclear program. Although these sites and activities constitute the most visible path to an Iranian bomb, other paths are possible as well. Furthermore, the more effectively an agreement constrains Iran's overt nuclear activities, the more likely it is to choose an alternative path if it decides to renege.

Specifically, this analysis considers three alternative paths:

1. "Covert/Make": Iran builds a covert enrichment program and a parallel covert weapons program.

2. "Covert/Buy": Iran buys a nuclear weapon from abroad.

3. Hybrid: Iran buys fissile material from a foreign seller and uses it in a local covert weapons program.

Reflection on alternative paths is not new and presumably has commanded the attention of Western intelligence agencies for years. The ongoing negotiations, however, present a unique opportunity to address these additional paths within the framework of a comprehensive nuclear agreement with Iran. 


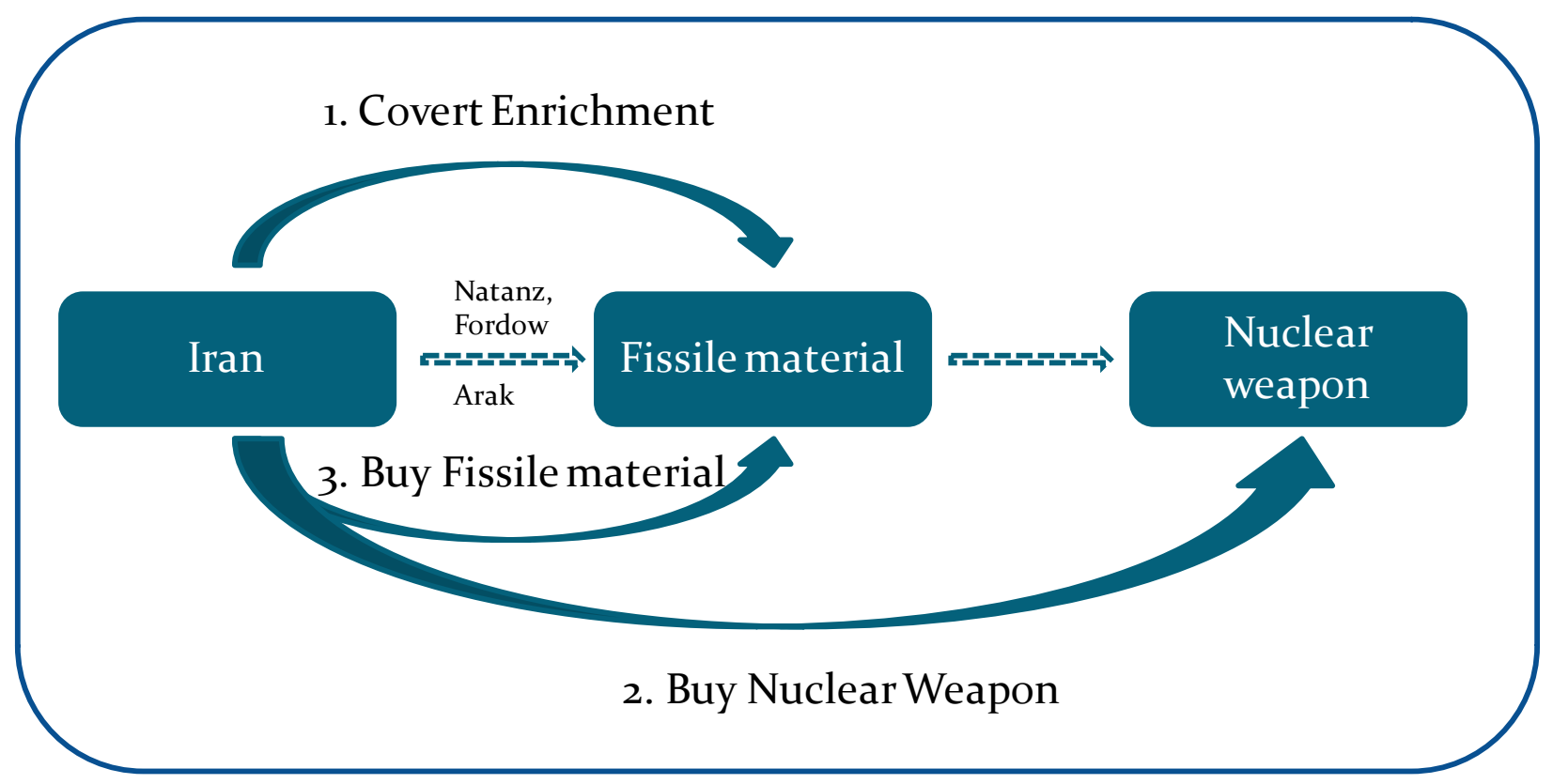

\section{Objective and Scope}

Our analysis aims to address the following challenge: how could a negotiated agreement assist in mitigating risks from all paths to an Iranian nuclear weapon?

In order to focus the analysis, we limit its scope in two aspects:

First, we deliberately refrain from analyzing both the overt elements of Iran's nuclear program (i.e., declared facilities at Natanz, Fordow, and Arak) and Iran's potential weapons-related activities (referred in IAEA parlance as Iran's "possible military dimensions"). ${ }^{3}$ These issues are already at the center of the ongoing negotiations and public discussion. ${ }^{4}$ Our analysis focuses instead on the alternative paths to an Iranian nuclear weapon, where there is no current, specific (public) information regarding their existence and characteristics. Second, our assessment is centered specifically on how an agreement can help address these alternative paths, given the possibility that an accord will indeed materialize in the coming months. ${ }^{5}$ Nonetheless, the results of this analysis might have potential implications for future intelligence efforts.

This figure is for illustration only. Most elements of the weaponization process could occur in parallel with the production of fissile material.

3 See the Annex to the IAEA report to the Board of Governors, 8 November 2011, http://www.iaea.org/Publications/ Documents/Board/2011/gov2011-65.pdf

4 For a comprehensive treatment of these issues, see Robert Einhorn, "Preventing a Nuclear-Armed Iran: Requirements for a Comprehensive Nuclear Agreement," Brookings Arms Control and Non-Proliferations Series, March 2014.

5 It is important to note, however, that President Obama put the odds of reaching a comprehensive nuclear agreement at no more than "50/50." See http://www.nytimes.com/2013/12/08/world/middleeast/obama-nuclear-deal-iran. $\underline{\text { html. }}$ 


\section{Methodology}

The key challenge is to find ways by which an agreement, which is detailed and specific, can address these alternative paths that are by definition abstract and not well-defined. We offer our thoughts in a two-step process:

First, for each alternative path, we analyze the potential obstacles Iran will face, and how they could be overcome. By addressing Iran's steps along each path, we increase the chances that they are well covered. Second, we suggest a number of different clauses that, if included in an agreement, would advance one of three objectives:

1. Decrease the probability of occurrence: The agreement could offer Iran incentives or propose joint activities that would make a covert nuclear weapons program less desirable and less feasible.

2. Increase the probability of early detection: The agreement could provide "trip-wires" (that is, agreed-upon safeguards) that enhance the ability of the IAEA (and intelligence agencies) to quickly detect Iranian activity on one or more of the alternative paths.

3. Provide a basis for intervention: When achieving stringent safeguards is impossible, another option is to define certain activities as breaches of the agreement, thus providing a basis for intervention. Just as member states have in the past provided intelligence to the IAEA on the possible military dimensions of Iran's nuclear program, information about such activities in the future, if acquired by other countries, would be provided to the IAEA for authentication. An independent assessment that a violation has occurred would then allow the P5+1 to take effective action to punish Iran.

In the analysis that follows, for each scenario, we analyze what Iran would have to do to obtain a nuclear weapon, what obstacles it would face, and how it could surmount those obstacles. Understanding this process will help negotiators identify where to focus their efforts in achieving an accord. We then propose specific items that could be included in a comprehensive nuclear agreement to reduce the probability of occurrence, increase the probability of early detection, or provide a basis for timely intervention.

\section{Path 1 (Covert/Make): Covert Enrichment ${ }^{6}$}

In a covert enrichment scenario, Iran would need to secretly build and operate an enrichment site separate from the Natanz and Fordow facilities. It would also require a supply of uranium hexaflouride gas $\left(\mathrm{UF}_{6}\right)$, as well as centrifuges and other auxiliary equipment. After enriching enough HEU for a bomb, Iran would then try to "weaponize," that is, to reconvert, mold, and integrate HEU into a deployable explosive device. ${ }^{7}$

\footnotetext{
6 One can envision a similar scenario in which Iran reprocesses spent fuel from the Bushehr or Arak reactors at a covert reprocessing facility to produce weapons-grade plutonium. This possibility is not analyzed in depth here, as a commitment not to reprocess is already covered in the JPOA and will probably be covered in a final nuclear agreement. The required analysis to determine risks of covert plutonium reprocessing would be similar to what is presented here.

As stated earlier, weaponization is not addressed in this analysis, since we assume barriers to weaponization are already a focus of the ongoing negotiations.
} 
The first step in this analysis is to consider what Iran needs to succeed on this path:

- Facilities: Iran has a number of underground facilities, some of which it could presumably convert into enrichment plants. ${ }^{8}$ Most of the preparatory work in building an infrastructure could be done (or may have already been done) with a very low profile.

- Equipment: We assume that in a negotiated agreement, Iran would be permitted only to continue using a part of its current nuclear capacity. This would, however, free up equipment that Iran could possibly use elsewhere, including a potential covert facility. Any equipment that could not be transported freely from overt facilities would need to be covertly manufactured or bought illicitly.

- Centrifuges: If stored centrifuges and centrifuge manufacturing plants are safeguarded, Iran would face a considerable challenge in manufacturing new ones (since covert manufacturing facilities would be difficult - but not impossible - to conceal for prolonged periods of time). However, Iran may have already set aside a number of centrifuges (of IR-1 or IR-2m types) to prepare for such an option.

- Auxiliary equipment: Building an enrichment plant also requires a number of supplementary items that are difficult to buy legitimately (because of limitations set by the Nuclear Suppliers Group and specific sanctions against Iran). However, such equipment could be transferred from idle or dismantled enrichment cascades at Natanz or Fordow to another location.

- Uranium: A major challenge to operating a covert enrichment program would be obtaining $\mathrm{UF}_{6}$. As the Uranium Conversion Facility in Isfahan has been under safeguards for several years, Iran would need to either circumvent safeguards at that facility or build a separate, covert conversion plant (unless such a stock or facility already exists).

- $\quad$ People/know-how: Building, commissioning, and operating an enrichment facility requires a significant number of personnel with experience in a wide variety of fields, including nuclear physics, engineering, software development, and construction. The expected decrease in activity at Natanz and Fordow may free up the necessary workforce, which would obviate the need for Iran to recruit and train a new cadre of specialists.

- Ongoing covert operation: The timeline for producing one bomb's worth of HEU is a function of the number and efficiency of the centrifuges at the site and the date they become (or became) operational. 6,000 IR-1 centrifuges spinning continuously and fed with natural uranium could produce one bomb's worth of HEU in less than 12 months. If Iran operated 3,000 more advanced IR-2m centrifuges, this could be achieved in about 4 months. ${ }^{9}$ Maintaining secrecy for the period required to construct and operate a covert site is a difficult task, as long as Iran remains under the lens of Western intelligence agencies.

How could an agreement help address the risk that Iran would choose this path?

\footnotetext{
For example, see http://www.nytimes.com/2010/01/06/world/middleeast/06sanctions.html.

9 Estimated timelines to a nuclear weapon at overt or covert facilities can be found at http://isis-online.org/uploads/ isis-reports/documents/Breakout_Study_24October2013.pdf.
} 
- Decrease the probability of occurrence:

- Initiate collaborative peaceful R\&D projects that will keep the scientific, engineering and technical personnel of Iran's nuclear program employed, engaged, and challenged in peaceful nuclear activities with international partners. While such programs could deepen Iranian scientists' understanding and expertise in nuclear matters, on-theground relationships could provide additional de facto monitoring.

- Allow (and require) Iran to meet its agreed-upon and verified enrichment-related purchasing needs through legitimate channels. ${ }^{10}$ For such a policy to succeed, Iran would have to provide full and verifiable end-user statements, which would be approved by the IAEA or the Joint P5+1-Iran Commission before a transaction takes place. This would reduce Iran's need to rely on illicit trade. Following such an arrangement, if an illicit transaction takes place or an invalid end-use is discovered, it would be considered a violation of the agreement.

- Increase the probability of early detection:

- In addition to existing safeguards on uranium conversion and monitoring of centrifuge production provided by the JPOA, establish limitations and safeguards on uranium mining and milling. Together these measures would help dissuade Iran from using existing infrastructure to produce centrifuges or $\mathrm{UF}_{6}$. The alternative - a completely new and covert infrastructure-would be costly and potentially detected. Since there is a chance that Iran has already set aside the necessary centrifuges and material, however, this requirement alone would be insufficient to shut down the covert/make pathway.

- Safeguard the use and storage of select dual-use equipment used for enrichment, such as motor drives and vacuum equipment (pumps, valves, gauges, etc.). While Iran could easily find a handful of units of each type of this equipment, a large-scale procurement effort would risk detection. Unless properly safeguarded, excess equipment left after a significant downsizing of the declared facilities could offer a readily available source.

- $\quad$ Provide a basis for intervention:

- Iran should make an explicit commitment to refrain from building and operating covert mining, conversion, centrifuge manufacturing and enrichment facilities.

- The P5+1 should pursue a UN Security Council resolution that compels the Council to take action if Iran is caught engaging in such covert activities.

${ }_{0}$ This assumes that, under a final agreement, Iran would still maintain some (limited) enrichment program. 


\section{Path 2 (Covert/Buy): Buying a complete nuclear weapon}

In this scenario, Iran would need to find a foreign supplier willing to sell a nuclear weapon (e.g., North Korea). Following the transaction, Iran would need to transfer the weapon(s) safely and securely to its intended destination and maintain high confidence that the weapon works, which would require various tests.

Once again, the first step in the analysis is to consider the steps required to obtain a bomb in this scenario:

- Finding a seller of nuclear weapons: A potential supplier would be North Korea. While this is not a very probable scenario, North Korea has in the past demonstrated its willingness to proliferate ballistic missiles and nuclear technology, despite clear and explicit warnings by the Bush administration not to do so. ${ }^{11}$ For instance, North Korea sold a plutonium-producing reactor to Syria, which would have by today produced enough plutonium for Syria's first nuclear bomb — had an aerial attack not destroyed the facility in 2007. What were the consequences? Syria lost its reactor, but North Korea was paid. North Korea has conducted three nuclear weapons tests, reprocessed enough plutonium for 10 weapons, and is now likely producing several bombs' worth of HEU each year. The sale of several weapons would thus not diminish North Korea's nuclear deterrent.

- Moving a nuclear weapon to Iran: In the hypothetical case of a North Korean weapon, transporting it to Tehran would not be a major obstacle. Today, ships and aircraft regularly transport items from North Korea to Iran and vice versa. An object as valuable as a nuclear weapon would likely be delivered directly by air. As the UN Panel of Experts has reported, items "can be sent by direct air cargo from North Korea to the destination country. Some modern cargo planes, for example, can fly non-stop from North Korea to Iran." ${ }^{12}$ Indeed, weapons delivery is not a hypothetical threat. In 2005, flouting the US-led Proliferation Security Initiative, North Korea sold to Tehran 18 intermediate-range ballistic missiles capable of striking targets in Europe and the Middle East.

- Evaluating the weapon's authenticity: A key obstacle in this scenario is Iran's ability to ensure that the nuclear weapon actually works. Such a task would probably include two parts:

- Iranian scientists and engineers would travel to North Korea to review design documents and records for quality assurance and perhaps attend various nuclear tests.

- Iran might conduct its own tests, including an underground controlled explosion.

\footnotetext{
${ }^{11}$ For example, see http://www.nytimes.com/2006/11/16/world/asia/16cnd-prexy.html?hp\&ex=1163739600\&en=5f7 eda6a9e220b4e\&ei=5094\&partner=homepage.

12 See http://www.un.org/ga/search/view_doc.asp?symbol=S/2010/571.
} 
Based on this analysis, how could an agreement help address the risk that Iran would choose this path?

- Iran could affirm its commitment to refrain from any nuclear-related collaboration with nonNPT countries (since we assess that this scenario would almost certainly entail technical discussions and meetings between the buyer and seller).

- Iran should ratify the CTBT and affirm its commitment to refrain from building facilities for underground nuclear testing (or declare such a facility if it exists).

\section{Path 3 (Hybrid): Buying or diverting fissile material for use in a covert program}

In this scenario, Iran would need to first identify a supplier - either a state or non-state organization-with weapons-usable HEU or plutonium. It would then need to transfer the material to Iran and store it safely and securely until a decision is taken to weaponize. Weaponization would then take place at a covert facility.

If it chooses this course of action, Iran would face the following obstacles:

- Finding a seller of fissile material: Over the past two decades, there have been a number of documented attempts by various state and non-state actors to buy or steal enough HEU or separated plutonium for a bomb. ${ }^{13}$ Despite significant progress in recent years, this remains a significant issue, particularly in the context of nuclear terrorism. Iran's access to funds for such a purchase is likely to be far greater than that available to non-state actors.

- $\quad$ Transferring material: Transporting fissile material bought abroad would be easier if the seller were a state (as discussed earlier), but could a rogue seller not do the same? Thousands of trucks, ships, and airplanes enter Iran every day. One or two of them could carry sufficient HEU or plutonium for several bombs.

- $\quad$ Storing fissile material: Iran could buy fissile material and store it for months or years as an "insurance policy" if it judges safeguards on enrichment to be effective enough to preclude enrichment of HEU. In this case, the material would have to be safely and secretly stored for what could be a lengthy period.

${ }_{13}$ See http://belfercenter.ksg.harvard.edu/publication/24014/advancing_nuclear_security.html. 
Based on this analysis, how could an agreement help address the risk that Iran would choose this path?

- Decrease the probability of occurrence:

- Invite Iran to participate in the Nuclear Security Summit process (beginning with the next summit in 2016) so that it would be (at least notionally) committed to assist in preventing illicit trade of nuclear materials.

- Provide a basis for intervention:

- Supplementing the Iranian Supreme Leader's fatwa against obtaining nuclear weapons, Iran could make a commitment not to have HEU or weapons-grade plutonium on Iranian soil (besides the two known existing stocks of HEU at research reactors in Tehran and Isfahan, amounting to roughly $7 \mathrm{~kg}$ ). If the IAEA or Western intelligence agencies were to discover such materials, Iran would be found in violation of the agreement.

In addition to what is achieved in a negotiated agreement, clarifying the past and present "possible military dimensions" of Iran's nuclear program could reduce risks that Iran would pursue this hybrid path. The sketch of this scenario also highlights the need for the relevant intelligence agencies to focus on monitoring collaboration between Iran and North Korea. 


\section{Conclusions}

Most public discussion has focused on Iran's most visible path to a nuclear weapon, namely the use of fissile material from Iran's declared and safeguarded facilities. There are, however, at least three additional paths by which Iran could obtain a nuclear bomb: enrich HEU at a covert facility, buy a weapon abroad, or a hybrid of the two. While ongoing negotiations are focused primarily on constraining the overt path, they also offer an opportunity to increase confidence that Iran will not be able to obtain a nuclear weapon along the other azimuths.

Having identified the main alternative paths and analyzed how Iran could overcome obstacles on each path to obtain a nuclear weapon, we propose for debate the following recommendations:

- To decrease the probability that Iran chooses one of these alternative paths:

- Initiate joint peaceful nuclear R\&D projects to engage Iran's cadre of nuclear specialists.

- Allow (and require) Iran to meet its verified enrichment-related purchasing needs through legitimate channels.

$\circ$ Invite Iran to participate in future Nuclear Security Summits.

- To increase the probability of early detection:

- Apply limitations and safeguards on uranium mining, milling, and conversion to $\mathrm{UF}_{6}$, and on centrifuge production (as done in the JPOA).

- Safeguard the use of existing centrifuges and enrichment-related auxiliary equipment.

- To provide a basis for intervention if Iran embarks on a covert path, Iran should commit (or reaffirm existing commitments) to:

- Refrain from building and operating covert mining, conversion, centrifuge manufacturing, and enrichment facilities.

- Discontinue any nuclear-related collaboration with non-NPT countries.

- Refrain from building facilities for underground nuclear testing (or declare such a facility, if it exists).

- Not import HEU or separated plutonium and not have these materials on Iranian soil (in addition to a commitment not to enrich to HEU or build a reprocessing plant).

In addition to these recommendations, we emphasize the need to clarify the "possible military dimensions" of Iran's nuclear program. Furthermore, while the focus of this analysis is to highlight opportunities for diplomacy, foreign intelligence agencies should adjust their efforts as necessary to concentrate on the alternative paths mentioned above. 


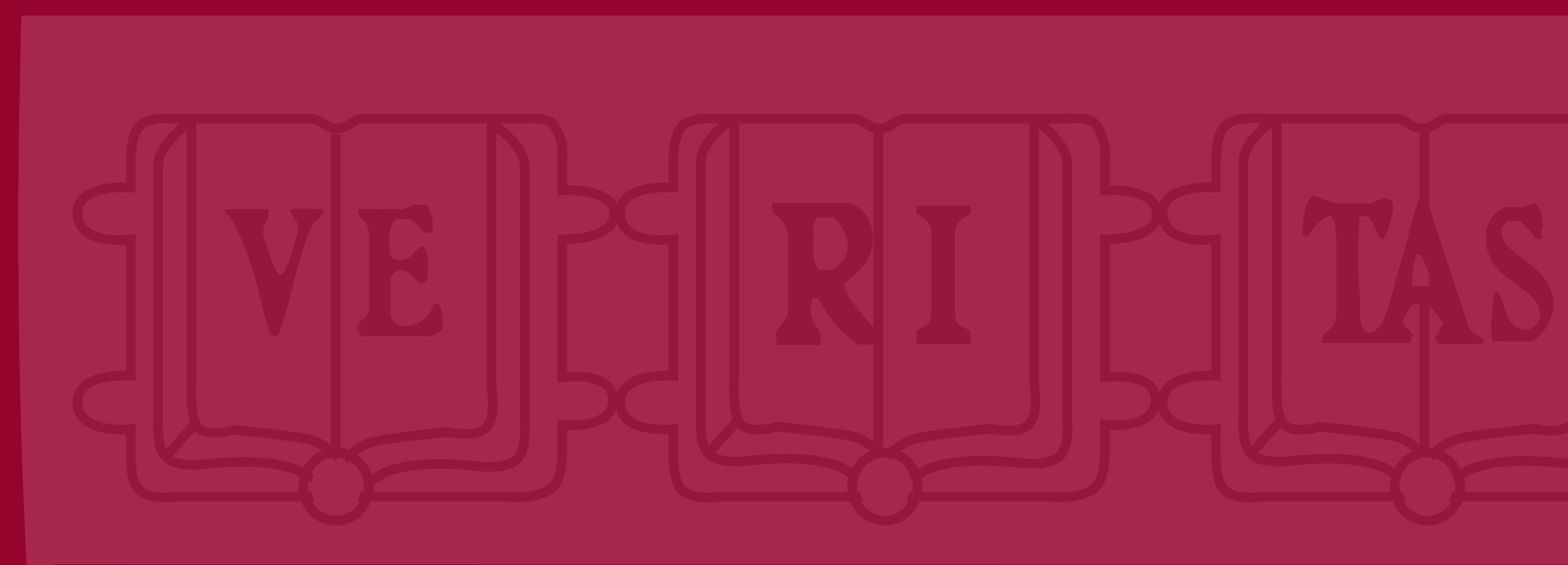

\section{Belfer Center for Science and International Affairs}

Harvard Kennedy School

79 JFK Street

Cambridge, MA 02138

Fax: (617) 495-8963

Email: belfer_center@harvard.edu

Website: http://belfercenter.org

Copyright 2014 President and Fellows of Harvard College 